\title{
Biological Activity of Synthetic Corticotrophin with Short Chain Lengths in the Rabbit
}

\author{
Shigeru MATSUKURA, Hideaki HigASHino, Noboru SAKAMOTO, \\ YUKIO HIRATA, AND HIROO IMURA
}

Third Division, Department of Medicine, Kobe University School of Medicine, Ikuta-ku, Kobe 650

\begin{abstract}
Synopsis
The adrenocorticotrophic effect of a synthetic substituted adrenocorticortophic

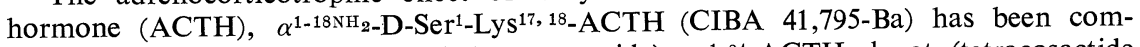
pared with that of $\alpha^{1-24}-\mathrm{ACTH}$ (tetracosactide), $\alpha^{1-24}-\mathrm{ACTH}$ depot (tetracosactide

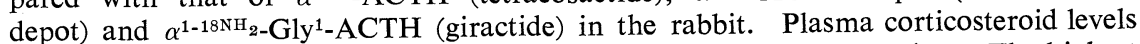
after saline injection were higher in the afternoon than in the morning. The highest value was observed at 3 p.m. 41,795-Ba, either given intravenously or intramuscularly, was shown to be the most potent peptide followed by tetracosactide depot and was 15 times more potent than tetracosactide and giractide in steroidogenic activity in the rabbit The intravenous administration of $41,795-\mathrm{Ba}$ caused more sustained stimulation of the adrenal cortex than the intramuscular injection. These results reveal the diurnal variation pattern of the pituitary-adrenal axis of the rabbit

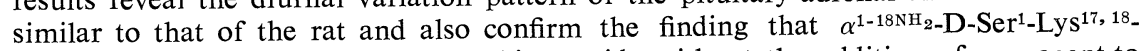
$\mathrm{ACTH}$ is a potent adrenocorticotrophic peptide without the addition of any agent to delay its absorption in the rabbit.
\end{abstract}

It is generally assumed that corticotrophins of various mammalian species have identical 1-24 amino acid sequence. Since the steroidogenic activity of corticotrophin has been shown to reside in this portion, especially in the first $18 \mathrm{~N}$-terminal amino acid sequence, many synthetic corticotrophin peptides with unmodified or modified $\mathrm{N}$ terminal amino acid sequence have been synthesized (Hofmann et al., 1962; Ramachandran and Li, 1967; Schwyzer, 1970). $\alpha^{1-24}-\mathrm{ACTH}$ and its depot preparation which have been shown to be sufficient for adrenalstimulating activity (Kappeler and Schwyzer, 1961) have been widely used in the treatment and diagnosis of various diseases.

\footnotetext{
Received for publication August 31, 1975.

We followed the nomenclature for ACTH structure proposed by Li (1959).
}

Recently, $\alpha^{1-18 \mathrm{NH}_{2}-\mathrm{Gly}^{1}-\mathrm{ACTH}}$ and $\alpha^{1-18 \mathrm{NH}_{2}}$ D-Ser ${ }^{1}$-Lys ${ }^{17,18-A C T H ~(O t s u k a ~ e t ~ a l ., ~} 1970$; Riniker and Rittel, 1970) have been synthesized and used clinically (Takebe et al., 1971; Keenan et al., 1971; Irvine et al., 1973). The comparisons of the steroidogenic effects of these synthetic peptide preparations have been studied in rats (Desaulles et al., 1968; Maier et al., 1971; Retiene et al., 1974) and in humans (Walser and Müller, 1968; Retiene et al., 1974; Irvine et al., 1974).

The present communication deals with the comparison of the steroidogenic activity of $\alpha^{1-24}-\mathrm{ACTH}, \quad$ its depot, $\alpha^{1-18 \mathrm{NH}_{2}-\mathrm{Gly}^{1}-}$

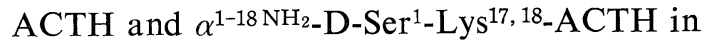
the rabbit. 


\section{Materials and Methods}

Peptides : $\quad \alpha 1$-18 $\mathrm{NH}_{2}$-D-Ser ${ }^{1}$-Lys17,18-ACTH (CIBA 41,795-Ba) (Riniker and Rittel, 1970), $\alpha 1-24-\mathrm{ACTH}$ (tetracosactide, Synacthen, Cortrosyn) (Kappeler and Schwyzer, 1961), $\alpha 1$-24-ACTH depot (tetracosactide depot, Synacthen depot, Cortrosyn depot) and $\alpha 1-18 \mathrm{NH}_{2}-\mathrm{Gly}^{1}$-ACTH (giractide, Acthormon) (Otsuka et al., 1970) were used.

Experimental procedures: Four male rabbits weighing $3.0-3.5 \mathrm{~kg}$ were kept on a standard laboratory diet and under controlled lighting conditions (6 a.m. -6 p.m.). Saline and all the peptides were given in succession to each of the four animals at intervals of ten days at least apart. Injections were given i.m. or i.v. at 9 a.m. Blood samples $(1 \mathrm{ml})$ were obtained by cardiac puncture $0,2,4,6,8,24$, 28 and $32 \mathrm{hr}$ after the injections. The total plasma corticosteroids consisting of corticosterone and cortisol were measured by competitive protein binding assay (Murphy, 1967) with the intra-assay variation being $7 \%$ and the inter-assay variation less than $15 \%$.

The areas under the curves of each mean value of plasma corticosteroids following any peptide injection were estimated planimetrically.

Statistical analysis was made by the Student's $t$ test.

\section{Results}

Saline control: Plasma corticosteroid levels in 4 rabbits after the intramuscular injection of saline are shown in Fig. 1. Basal plasma corticosteroid level at 9 a.m. of $1.1 \pm 0.3 \mu \mathrm{g} / \mathrm{d} l$ (mean $\pm \mathrm{SE}$ ) ranging from 0.3 to $1.8 \mu \mathrm{g} / \mathrm{d} l$ increased in the afternoon to a peak level of $3.5 \pm 0.4 \mu \mathrm{g} / \mathrm{d} l$ with the range of $2.5-4.4$ at 3 p.m. The values subsequently declined to almost undetectable levels by 9 a.m. of the next day. The values at 1 p.m., 3 p.m. and 5 p.m. were significantly higher than those at 9 a.m. $(\mathrm{P}<0.05)$.

CIBA 41,795-Ba: The plasma corticosteroid levels after the intravenous and intramuscular injection of $0.5 \mathrm{mg}$ of $41,795-\mathrm{Ba}$ are shown in Fig. 2. Both intravenous and intramuscular administration of the peptide caused a rapid increase in plasma corticosteroids with the highest values of $11.5 \pm 2.4$ $\mu \mathrm{g} / \mathrm{d} l($ mean $\pm \mathrm{SE}$ ) at $4 \mathrm{hr}$, and $13.1 \pm 2.7 \mu \mathrm{g} / \mathrm{d} l$ at $2 \mathrm{hr}$, respectively. Plasma corticosteroid levels remained elevated up to $32 \mathrm{hr}$ after the intravenous injection, while they returned to the preinjection level $24 \mathrm{hr}$ after the intramusculr injection. The area under the curve of mean values of plasma corticosteroids after the intravenous injection was greater than that after the intramuscular injection (Table 1), suggesting that the

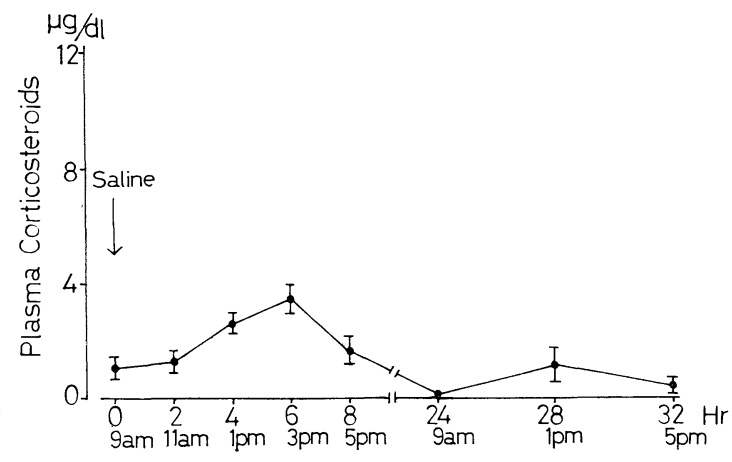

Fig. 1. Plasma corticosteroid levels in rabbits after a single intramuscular injection of saline at 9 a.m. Each point is the mean value obtained from 4 rabbits \pm SEM. The values at 1,3 and 5 p.m. were significantly different from those at 9 a.m. by Student's $t$ test $(\mathrm{P}<0.05)$, showing a diurnal variation pattern opposite to that of man.

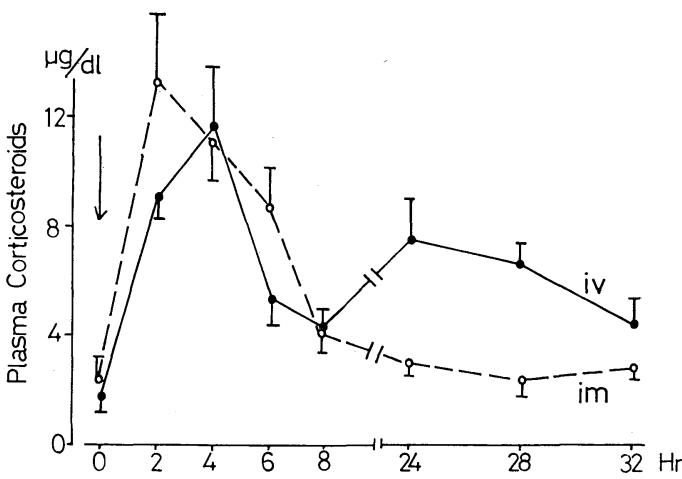

Fig. 2. Time course of plasma corticosteroid levels in rabbits after a single intravenous (solid line) or intramuscular (broken line) injection of $0.5 \mathrm{mg}$ of 41,795-Ba. Each point represents the mean of 4 rabbits \pm SEM. 
intravenous administration had a greater steroidogenic effect than the intramuscular administration. The intravenous dose of $0.1 \mathrm{mg}$ of the peptide resulted in an elevation of plasma corticosteroids of the same magnitude but shorter duration (Fig. 3).

Tetracosactide depot: The intramuscular injection of $0.5 \mathrm{mg}$ of tetracosactide depot caused stimulation of the adrenals that persisted for $8 \mathrm{hr}$ after the administration (Fig. 4). The integrated levels of plasma corticosteroids after the injection of $0.5 \mathrm{mg}$ of tetracosactide depot are less than those after the intramuscular administration of $0.5 \mathrm{mg}$ of $41,795-\mathrm{Ba}$ (Table 1), suggesting that the steroidogenic activity of $41,795-\mathrm{Ba}$ given intramuscularly was greater than that of tetracosactide depot.

Tetracosactide and Giractide: Following the intravenous administration of $0.5 \mathrm{mg}$ of either peptide the concentration of plasma corticosteroids rose to a peak at $2 \mathrm{hr}$ and then decreased to the base-line levels at $4 \mathrm{hr}$, indicating a much shorter duration of action as compared with 41,795-Ba (Fig. 5). Considering the ratio of the integrated levels of plasma corticosteroids after the intravenous injection of $0.5 \mathrm{mg}$ of $41,795-\mathrm{Ba}$, tetracosactide and giractide, 41,795-Ba was found

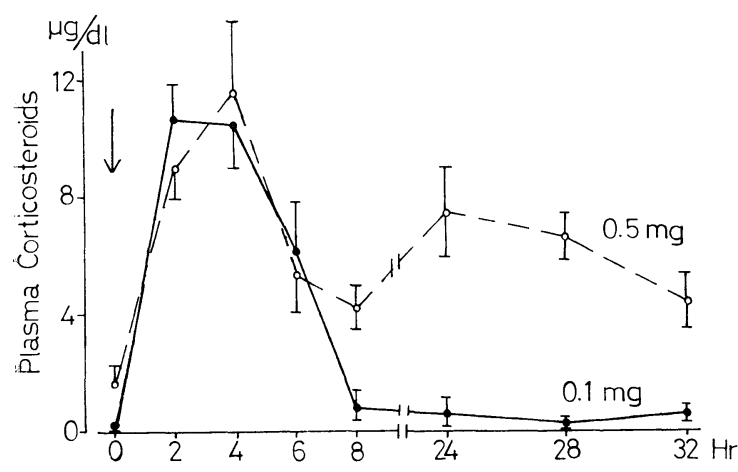

Fig. 3. Time course of plasma corticosteroid levels in rabbits after a single intravenous injection of $0.1 \mathrm{mg}$ (solid line) or $0.5 \mathrm{mg}$ (broken line) ot 41,795-Ba. Each point represents the mean of 4 rabbits \pm SEM.

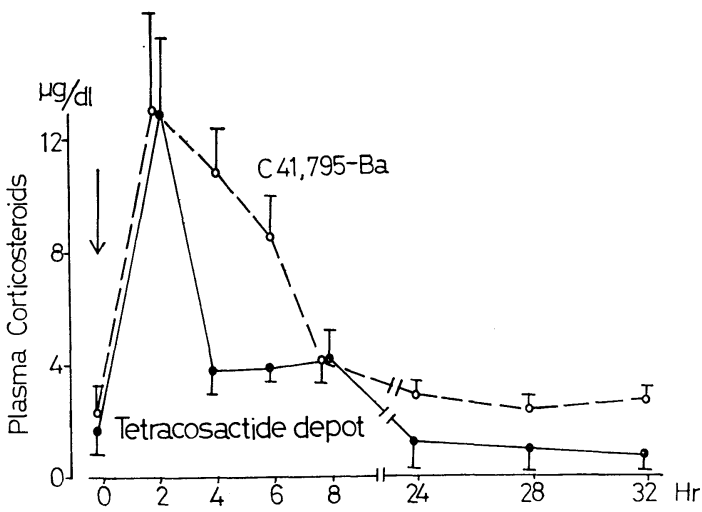

Fig. 4. Time course of plasma corticosteroid levels in rabbits after a single intramuscular injection of $0.5 \mathrm{mg}$ of tetracosactide depot (solid line) or of 41,795-Ba (broken line). Each point represents the mean of 4 rabbits \pm SEM.

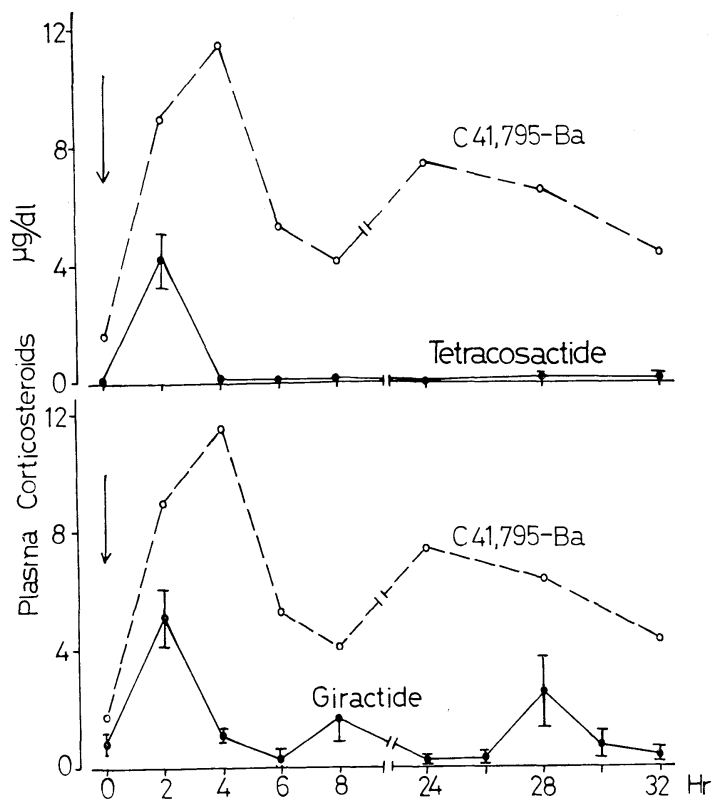

Fig. 5. Time course of plasma corticosteroid levels in rabbits after a single intravenous injection of $0.5 \mathrm{mg}$ of tetracosactide (solid line, upper panel) and of giractide (solid line, lower panel) or of 41,795-Ba (broken line). Each point represents the mean of 4 rabbits \pm SEM. 
to be 15 times more potent than tetracosactide and giractide (Table 1).

Side effects: The rabbits became calm and motionless for 2 to $4 \mathrm{hr}$ after the intravenous injection of all of the peptide, especially $0.5 \mathrm{mg}$ of $41,795-\mathrm{Ba}$. These effects may be due to the release of histamine (Jacques and Brugger, 1969) or other bioactive substances.

\section{Discussion}

The quick blood drawing by the cardiac puncture in the rabbits does not seem to act as a stress since plasma corticosteroid levels remained in the low range after the saline injection in our present experiments. Plasma corticosteroid levels in the rabbits were higher in the afternoon than in the morning with the peak at 3 p.m., indicating that the rabbit had a diurnal variation pattern of the pituitary-adrenal axis similar to that of the rat (Retiene et al., 1968; Matsuyama et al., 1971).

In the present experiments in which rabbits were used, 41,795-Ba was the most potent peptide in steroidogenic activity when compared with tetracosactide depot, tetracosactide and giractide given by the same route and similar doses. Since blood samples were obtained at $2 \mathrm{hr}$ intervals, the peak in plasma corticosteroid levels might have been missed especially in the case of the peptides with a shorter duration of action. Nevertheless, the fact that the integrated increment of plasma corticosteroids following the intravenous administration of $41,795-\mathrm{Ba}$ was 15 times greater than that of tetracosactide or giractide demonstrated clearly the greater potency and sustained steroidogenic activity of the former peptide without the addition of any agent to delay its absorption. In rats, Maier et al. (1971) observed that $41,795-\mathrm{Ba}$ was 10 times more potent than tetracosactide in the in vivo steroidogenic effect when threshold doses
Table 1. The integrated increment of plasma corticosteroid levels after the injection of synthetic corticotrophin peptides with short chain lengths.

\begin{tabular}{lclcc}
\hline \multicolumn{1}{c}{ Peptides } & $\begin{array}{c}\text { Routes of } \\
\text { administ- } \\
\text { ration }\end{array}$ & Doses & $\begin{array}{l}\text { Integrated } \\
\text { Increment* }\end{array}$ & $\begin{array}{c}\text { Ratio of } \\
\text { potency }\end{array}$ \\
\hline $41,795-\mathrm{Ba}$ & i.v. & $0.1 \mathrm{mg}$ & 67 & 7 \\
$41,795-\mathrm{Ba}$ & i.v. & 0.5 & 147 & 15 \\
$41,795-\mathrm{Ba}$ & i.m. & 0.5 & 78 & 8 \\
$\begin{array}{l}\text { tetracosactide } \\
\quad \text { depot }\end{array}$ & i.m. & 0.5 & 55 & 6 \\
$\begin{array}{l}\text { tetracosactide } \\
\text { giractide }\end{array}$ & i.v. & 0.5 & 9 & 1 \\
\hline
\end{tabular}

*The area under the curve of plasma corticosteroids is estimated planimetrically from the time course of mean plasma corticosteroid values of 4 rabbits after the injection of peptide and expressed with an arbitrary unit.

were compared. They reported also that 41,795-Ba was 100 times more potent when the doses producing equal area under the timecurve were compared (Maier et al., 1971).

With respect to a comparison of routes of administration, the duration of action and the integrated levels of plasma corticosteroids were greater after the intravenous than the intramuscular injections of $0.5 \mathrm{mg}$ of $41,795-\mathrm{Ba}$ in the present study. The duration of action of $41,795-\mathrm{Ba}$ was reported to be longer after the intravenous than the subcutaneous injections in rats (Maier et al., 1971) and in humans (Komanicky et al., 1975). These findings could be explained by the higher concentration of the peptide reaching the adrenal cortex when given intravenously. After intramuscular administration, 41,795-Ba was found to be more potent than tetracosactide depot in the rabbit. In contrast, in humans Irvine et al. (1974) reported that the duration of action of intramuscular injections of tetracosactide depot was longer than that of $41,795-\mathrm{Ba}$. This discrepancy could be due to the difference of species and doses used in both studies.

At present, the mechanism of the prolonged and potent steroidogenic activity of $41,795-\mathrm{Ba}$ is not clear. We previously reported that corticotrophins with shorter chain lengths were generally less stable than 
peptides with longer chain lengths when incubated in vitro in the presence of plasma and that the presence of the carboxamide at the C-terminal end might protect corticotrophin from the enzymatic degradation (Imura et al., 1967). Boissonas et al. (1966) observed that the substitution of D-serine for L-serine at the $\mathrm{N}$-terminal retarded degradation of corticotrophin by aminopeptidase resulting in a potentiation of steroidogenic activity. It is also possible that the presence of $\mathrm{Lys}^{17,18}$ substituted for $\mathrm{Arg}^{17,18}$ at the proposed "binding sites" of the ACTH molecule (Hofmann, 1960 ; Ramachandran and Li, 1967) could augment binding of the peptide on recepters of the adrenal cortex resulting in the increased steroidogenesis. Recently Finn et al. (1972) reported, however, that $41,795-\mathrm{Ba}$ whose in vivo and in vitro steroidogenic activity was higher than that of $\alpha^{1-23}-\mathrm{ACTH}$ or $\alpha^{1-24}-\mathrm{ACTH}$ competed with radioactive ACTH for binding to the membrane preparation of the adrenal cortex as effectively as $\alpha^{1-23}-\mathrm{ACTH}$ and was rather less active in activating adrenal adenyl cyclase than $\alpha^{1-24}$ ACTH, although steroidogenic responses did not occur in parallel with an increase in cyclic AMP production beyond a certain large dose of ACTH given (Grahame-Smith et al., 1967). Moreover, Desaulles et al. (1968) reported that in rats L-serine analogue of 41,795-Ba elicited a shorter and less sustained steroidogenic response than tetracosactide. These data indicate that the apparently higher potency of $41,795-\mathrm{Ba}$ was neither the result of greater affinity for the binding sites nor more activation of adenyl cyclase but rather a reflection of the increased stability to cleavage by exopeptidases. The longer activity of 41,795 -Ba could therefore be explained by the slow degradation in the peripheral circulation and/or in the receptor sites of the adrenal cortex.

\section{References}

Boissonas, R.A., S.T. Guttmann and J. Pless (1966). Experientia 22, 526.

Desaulles, P. A., B. Riniker and W. Rittel. Protein and Polypeptide Hormones, Excerpta Med. (Amst.) p. 489 (1968).

Finn, F. M., C. C. Windell and K. Hofmann (1972). J. Biol. Chem. 247, 5695.

Grahame-Smith, D. G., R. W. Butcher, R.L. Ney and E.W. Sutherland (1967). J. Biol. Chem. 242, 5535.

Hofmann, K. (1960). Brookhaven Symp. Biol. 13, 184.

Hofmann, K., H. Yajima, T. Y. Liu and N. Yanaihara (1962). J. Amer. Chem. Soc. 84, 4475.

Imura, H., H. Matsuyama, S. Matsukura, T. Miyake and M. Fukase (1967). Endocrinology 80, 599.

Irvine, W. J., K. S. Wilson and A. D. Toft (1973). Lancet 1, 1417.

Irvine, W. J., A. D. Toft, K. S. Wilson, R. Fraser, A. Wilson, J. Young, W. M. Hunter, A. A. A. Ismail and P. E. Burger (1974). J. Clin. Endocr. 39, 522.

Jacques, R. and M. Brugger (1969). Pharmacology 2, 361 .

Kappeler, H. and R. Schwyzer (1961). Helv. Chim. Acta 44, 1136.

Keenan, J., J. B. Thompson, M. A. Chamberlain and G.M. Besser (1971). Brit. Med. J. 3, 742.

Komanicky, P., S. L. Dale and J. C. Melby (1975). Abstract of 57th Annual Meeting of The Endocrine Society of U. S. A., p. 265.

Li, C. H. (1959). Science 129, 969.

Maier, R., P.L. Barthe, L. Schenkel-Hulliger and P. A. Desaulles (1971). Acta Endocr. 68, 458.

Matsuyama, H., A. Ruhman-Wennhold and D. H. Nelson (1971). Endocrinology 88, 692.

Murphy, B. E. P. (1967). J. Clin. Endocr. 27, 973.

Otsuka, H., M. Shin, Y. Kinomura and K. Inoue (1970). Bul. Chem. Soc. Jap. 43, 196.

Ramachandran, J. and C. H. Li (1967). Adv. Enzymol. 29, 391.

Retiene, K., E. Zimmerman, W. J. Schindler, J. Neuenschwander and H.S. Lipscomb (1968). Acta Endocr. 57, 615.

Retiene, K., F. Schulz, J. Kutchera and H. Schierle (1974). Arzneim. Forsch. 24, 1057.

Riniker, B. and W. Rittle (1970). Helv. Chim. Acta 53, 513.

Schwyzer, R. (1970). Experientia 26, 577.

Takebe K., H. Kunita, M. Sakakura, Y. Horiuchi and K. Mashimo (1971). J. Clin. Endocr. 33, 356.

Walser, A. and Th. Müller. Protein and Polypeptide Hormones, Excepta Med., (Amst.) p. 487. (1968). 